\title{
Effect of dexmedetomidine on intraoperative Surgical Pleth Index in patients undergoing video-assisted thoracoscopic lung lobectomy
}

Yu-Lan Wang ${ }^{\dagger}$, Xiao-Qi Kong ${ }^{\dagger}$ and Fu-Hai Ji

\begin{abstract}
Background: The Surgical Pleth Index (SPI) is a monitoring method that reflects painful stimuli during general anesthesia, and dexmedetomidine is an analgesic adjuvant with an opioid-sparing effect. But up to now, it is still unclear whether dexmedetomidine has any influence on SPI. To investigate whether dexmedetomidine has an effect on SPI during video-assisted thoracoscopic surgery.

Methods: We enrolled 94 patients who underwent video-assisted thoracoscopic lung lobectomy. Patients were randomly assigned to a dexmedetomidine group (dexmedetomidine: $0.8 \mathrm{\mu g} / \mathrm{kg}$ administered for $10 \mathrm{~min}$ before anesthesia) or normal saline group (equal volume of normal saline). SPI and vital signs were recorded. The number rating scale (NRS) pain score was also evaluated.

Results: SPI values were significantly lower in the dexmedetomidine group than in the normal saline group at intubation and at discharge from the postanesthesia care unit. Compared with the normal saline group, mean arterial pressure and heart rate were both significantly lower in the dexmedetomidine group at intubation. Heart rate was lower at skin incision in the dexmedetomidine group. The NRS score in the normal saline group was noticeably higher vs. the dexmedetomidine group at discharge from the postanesthesia care unit.
\end{abstract}

Conclusions: Dexmedetomidine decreased intraoperative SPI and NRS scores. Our results showed that dexmedetomidine attenuated noxious stimuli.

Trial registration: Chinese Clinical Trial Registry (ChiCTR): ChiCTR-OOC-16009450, Registered 16 October, 2016.

Keywords: Surgical Pleth index, Dexmedetomidine, Number rating scale, Thoracoscopic lung lobectomy

\section{Background}

Video-assisted thoracoscopic surgery (VATS) is being performed more frequently. However, although thoracoscopic lung lobectomy is less traumatic than open thoracotomy, patients still experience significant pain $[1,2]$. The Surgical Pleth Index (SPI), formerly, the "surgical

\footnotetext{
* Correspondence: jifuhai@hotmail.com

${ }^{\dagger}$ Yu-Lan Wang and Xiao-Qi Kong contributed equally to this work. Department of Anesthesia Surgery, The First Affiliated Hospital of Soochow University, 188 Shizi Street, Suzhou 215006, Jiangsu, China
}

stress index", is a monitoring method for patients' responses to surgical stimulation without injury. SPI can be used to monitor patients' hemodynamic responses during general anesthesia because SPI reflects the increased sympathetic activity of the patient in response to painful (nociceptive) stimuli. The SPI value is obtained from photoplethysmographic amplitude (PPGA) and heart rate $(\mathrm{HR})$ data from pulse oximetry measurements $[3,4]$. Studies demonstrate that SPI can detect the balance between nociceptor activation and analgesia better

(c) The Author(s). 2020 Open Access This article is licensed under a Creative Commons Attribution 4.0 International License, which permits use, sharing, adaptation, distribution and reproduction in any medium or format, as long as you give appropriate credit to the original author(s) and the source, provide a link to the Creative Commons licence, and indicate if changes were made. The images or other third party material in this article are included in the article's Creative Commons licence, unless indicated otherwise in a credit line to the material. If material is not included in the article's Creative Commons licence and your intended use is not permitted by statutory regulation or exceeds the permitted use, you will need to obtain permission directly from the copyright holder. To view a copy of this licence, visit http://creativecommons.org/licenses/by/4.0/ The Creative Commons Public Domain Dedication waiver (http://creativecommons.org/publicdomain/zero/1.0/) applies to the data made available in this article, unless otherwise stated in a credit line to the data. 
than other parameters, including HR and blood pressure (BP) $[5,6]$. Therefore, SPI can estimate intraoperative nociception. SPI ranges from 0 to 100 , and higher values indicate stronger stimuli during surgery [7].

Dexmedetomidine is a short-acting $\mathrm{a}_{2}$-adrenoceptor agonist that provides sedation and analgesia $[8,9]$. Studies show that dexmedetomidine attenuates surgical stress responses in patients undergoing surgery $[10,11]$, and, as an adjunctive analgesic, can be safely and effectively used during surgery. Currently, because of its characteristics, some anesthesiologists in clinical practice use dexmedetomidine as an auxiliary drug during anesthesia; however, other anesthesiologists do not use this drug because of a fear of significantly decreasing HR, and they choose other sedative drugs, such as midazolam.

Although thoracoscopic surgery is relatively less invasive, patients still experience moderate-intensity pain. SPI reflects intraoperative stress, and dexmedetomidine can weaken the surgical stress response. But up to now, it is still unclear whether dexmedetomidine has any influence on SPI. The aim of our study is to determine whether dexmedetomidine can reduce the SPI value during surgery, by investigating the effect of dexmedetomidine on SPI in patients undergoing VATS lung lobectomy.

\section{Methods}

\section{Study population}

This was a randomized, prospective clinical study. This study was approved by the ethics committee of our hospital, written informed consent was obtained from all patients prior to study participation. This study was registered in Chinese Clinical Trial Registry with the number ChiCTR-OOC-16009450. Patients were selected if they met the following criteria: clinical diagnosis of lung cancer limited to one lung, age 18-75 years, body mass index (BMI) $18-30 \mathrm{~kg} / \mathrm{m}^{2}$, and American Society of Anesthesiologists physical status grade (ASA) I-II. The exclusion criteria were severe cardiovascular disease; second- or third-degree atrioventricular block on electrocardiography; history of renal, endocrine or neurological diseases; preoperative oral analgesic drugs; alcoholism; and pregnancy.

We enrolled 94 patients who were randomly divided into either a dexmedetomidine group or a normal saline group. In the dexmedetomidine group, dexmedetomidine $0.8 \mu \mathrm{g} / \mathrm{kg}$ was administered for $10 \mathrm{~min}$ before anesthesia. The normal saline group received the same volume of normal saline.

\section{Anesthetic management}

Patients received no premedication. After entering the operating room, patients were monitored using invasive BP (radial arterial BP), HR, pulse oximetry, and electrocardiography. The SPI value was measured using the
Datex-Ohmeda S/5 ADU (GE Healthcare, Madison, WI) monitoring system. Peripheral venous access was established, and all patients underwent endobronchial anesthesia. Anesthesia induction involved intravenous fentanyl $(4.0 \mu \mathrm{g} / \mathrm{kg})$, propofol $(2.0 \mathrm{mg} / \mathrm{kg})$, and cisatracurium $(0.15 \mathrm{mg} / \mathrm{kg})$. Endobronchial intubation was performed once the injectable anesthetics were effective. One-lung ventilation was continued from skin incision to skin closure and using $100 \%$ oxygen. Intraoperative end-tidal carbon dioxide was maintained at 35-45 $\mathrm{mmHg}$ by adjusting the ventilation rate and tidal volume. Anesthesia was maintained with $2.0-3.0 \%$ isoflurane, fentanyl $(2.0 \mu \mathrm{g} / \mathrm{kg})$, and cisatracurium $(0.10 \mathrm{mg} / \mathrm{kg} /$ h). During surgery, we ensured that patients' $\mathrm{BP}$ and HR fluctuations did not exceed $20 \%$ of their preoperative baseline values by modulating the narcotic drugs that we administered. Intraoperative anesthetic drug administration still depended on conventional empirical approaches according to changes in $\mathrm{BP}$ and $\mathrm{HR}$ to maintain anesthesia depth. If HR fell below $50 \mathrm{bpm}$, we administered $0.01 \mathrm{mg} / \mathrm{kg}$ atropine intravenously. If systolic pressure dropped below $90 \mathrm{mmHg}$, we administered $0.1 \mathrm{mg} / \mathrm{kg}$ ephedrine intravenously. Following surgery, all patients were transported to the post anesthesia care unit (PACU).

\section{Data collection}

SPI, HR, and BP were recorded when the patient entered the operating room (baseline), at intubation, at the beginning of the operation (skin incision), end of the operation (skin closure), and at PACU discharge. The depth of sedation was assessed using the Observer's Assessment of Alertness/Sedation (OAA/S) scale $10 \mathrm{~min}$ after extubation $(5=$ responds readily to name spoken in a normal tone; $4=$ lethargic response to name spoken in a normal tone; $3=$ responds only after name is called loudly or repeatedly; 2 = responds only after mild prodding or shaking; $1=$ does not respond to mild prodding or shaking). Patients used the numerical rating scale (NRS) $(0=$ no pain and $10=$ the worst pain $)$ to rate their pain, and we evaluated the NRS scores at PACU discharge and 24 or $48 \mathrm{~h}$ after surgery.

\section{Statistical analysis}

Data were analyzed using SPSS version 19.0 (IBM Corp., Armonk, NY). Continuous normally-distributed data were compared using Student's t-test. Non-continuous and non-normally distributed data were analyzed using the Mann-Whitney test. Results were expressed as means \pm standard deviations or as medians. Categorical variables were analyzed using the $X^{2}$ test, and $P<0.05$ was considered statistically significant between groups. 


\section{Results}

\section{Patients' characteristics}

Four patients were excluded. One patient was excluded because of a significant decrease in $\mathrm{HR}(<45 \mathrm{bpm})$ during surgery in the dexmedetomidine group, and three patients were excluded in the normal saline group. Two were excluded due to conversion to thoracotomy, and one was excluded due to major intra-operative bleeding. A final 90 patients were enrolled in the study; 46 in the dexmedetomidine group and 44 in the normal saline group. Patients' baseline characteristics (age, sex, ASA status, weight, and BMI) did not differ between the two groups (Table 1). The length of surgery and anesthesia also did not differ between the two groups. Anesthetic dosages trended downward in the dexmedetomidine group, but there was no significant difference between the two groups. The total amount of propofol used, and the extubation time and Observer's Assessment of Alertness/Sedation score in the PACU did not differ between the groups (Table 1).

\section{SPI value}

SPI values showed no significant differences between the groups at baseline, at skin incision, and at skin closure. Compared with the normal saline group, SPI values in the dexmedetomidine group were lower at intubation (53.61 \pm 15.03 vs. $63.14 \pm 16.60$, respectively; $P=0.005$ ) and at PACU discharge $(53.37 \pm 14.98$ vs. $60.11 \pm 16.60$, respectively; $P=0.046$ ) (Fig. 1 ).

\section{Hemodynamic parameters}

Mean BP was higher in the normal saline group than in the dexmedetomidine group at intubation (99.57 \pm 12.97 vs. $91.74 \pm 15.37$, respectively; $P=0.011$ ) (Fig. 2 ). HR was lower in the dexmedetomidine group compared with the normal saline group at intubation $(66.80 \pm 9.66$ vs. $71.86 \pm 10.25$, respectively; $P=0.018)$ and at skin incision $(61.39 \pm 12.05$ vs. $67.20 \pm 15.01$, respectively; $P=0.045)$ (Fig. 2).

\section{NRS pain score}

Surgical resections were performed using a two-port approach in the two groups, and a chest tube ( $28 \mathrm{Fr}$ ) was placed at the end of the surgery. The NRS pain scores in the normal saline group were higher than in the dexmedetomidine group at PACU discharge (3.25 \pm 1.37 vs. $2.67 \pm 0.82$, respectively; $P=0.018$ ). However, there were no remarkable differences in pain scores between the two groups 24 or $48 \mathrm{~h}$ postoperatively (Fig. 3).

\section{Discussion}

In this study, dexmedetomidine administered before anesthesia decreased patients' SPI values and pain scores, and dexmedetomidine led to more stable intraoperative hemodynamics.

VATS has been widely used to treat lung cancer because it is minimally invasive, more effectively decreases postoperative pain compared with open thoracotomy, and shortens hospital stay [12]. However, postoperative pain management, particularly early postoperative pain, remains a matter of concern for many anesthesiologists [2, 13]. Opioids are essential during surgery; however, reducing opioid consumption has become important because of their side effects, such as delayed recovery from general anesthesia, opioid-induced nausea, and respiratory depression $[14,15]$. Reducing the use of opioids during surgery improves patients' postoperative recovery. Intraoperative dexmedetomidine improves the effects of postoperative analgesia [16-18], and as an adjunct to general anesthesia, dexmedetomidine has

Table 1 Patients' baseline characteristics

\begin{tabular}{|c|c|c|c|}
\hline & $\begin{array}{l}\text { Dexmedetomidine group } \\
(n=46)\end{array}$ & $\begin{array}{l}\text { Normal saline group } \\
(n=44)\end{array}$ & $P$ value \\
\hline Male/female (n) & $17 / 29$ & $22 / 22$ & 0.212 \\
\hline ASA I/II (n) & $7 / 39$ & $10 / 34$ & 0.391 \\
\hline Age (year) & $56.78 \pm 12.81$ & $60.48 \pm 12.58$ & 0.171 \\
\hline Weight (kg) & $58.48 \pm 10.09$ & $61.77 \pm 8.71$ & 0.101 \\
\hline $\mathrm{BMI}\left(\mathrm{kg} / \mathrm{m}^{2}\right)$ & $22.09 \pm 3.22$ & $22.89 \pm 2.85$ & 0.217 \\
\hline Duration of surgery (min) & $162.37 \pm 59.62$ & $159.95 \pm 60.59$ & 0.849 \\
\hline Duration of anesthsia (min) & $191.35 \pm 62.26$ & $203.27 \pm 53.41$ & 0.333 \\
\hline Fentanyl used during surgery (mg) & $0.49 \pm 0.07$ & $0.52 \pm 0.08$ & 0.086 \\
\hline Propofol used during surgery (mg) & $116.70 \pm 20.30$ & $123.75 \pm 17.71$ & 0.083 \\
\hline Time of extubation (min) & $18.41 \pm 11.97$ & $17.59 \pm 12.20$ & 0.748 \\
\hline OAA/S & $4.41 \pm 0.54$ & $4.59 \pm 0.54$ & 0.123 \\
\hline
\end{tabular}

Data are presented as mean \pm standard deviation or number

ASA American Society of Anesthesiologists, BMI body mass index, OAA/S Observer's Assessment of Alertness/Sedation 


\section{$\square$ dexmedetomidine group \\ $\square$ normal saline group}

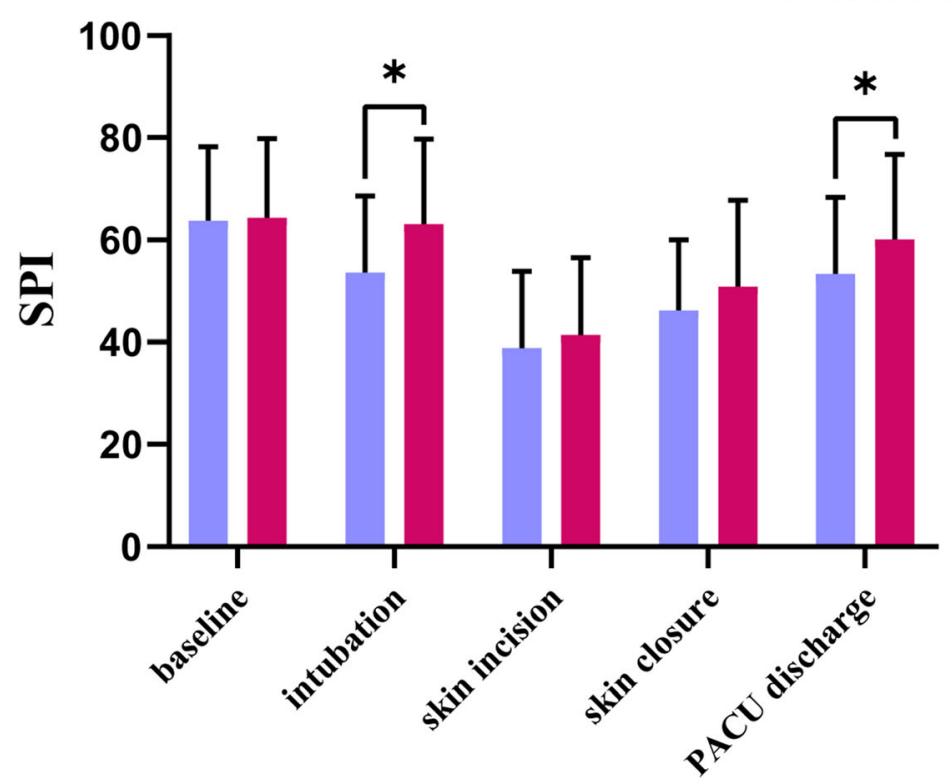

Fig. 1 Comparison of SPI values between the two groups undergoing video-assisted thoracoscopic lung lobectomy from the time patients entered the operating room to when they left the recovery room. SPI: Surgical Pleth Index, PACU: post anesthesia care unit, ${ }^{*} P<0.05$

analgesic, sedative, and anxiolytic effects, and avoids respiratory depression and the inhibitory effect of sympathetic stimulation $[8,9]$. Dexmedetomidine maintains the stability of the cardiovascular system and decreases the stress response [10]. Many studies have shown that dexmedetomidine has opioid-sparing properties $[19,20]$ and that it maximizes pain relief and minimizes analgesic-related side effects [21]. In this study, dexmedetomidine used before anesthesia decreased NRS scores in the PACU. Although dexmedetomidine did not decrease the amount of fentanyl required, we saw a trend towards less fentanyl use.

SPI is calculated by heart beat intervals (HBI) and PPGA, both of which are obtained from pulse oximetry [4]. SPI values, which indicate surgical stress reactions, range between 0 and 100 , with 0 representing the lowest stimulus response and 100 representing the highest level of stimulation. High SPI values are considered indicators of a prevalence of nociception over antinociception [7]. Surgical procedures under general anesthesia elicit a variety of stress responses that induce negative influences and that eventually negatively affect patients' prognosis $[22,23]$. SPI reflects the relationship between surgical stimulation intensity and antinociception during general anesthesia; higher values indicate stronger stimuli $[4,22,24-26]$.
Therefore, SPI is more predictable for measuring autonomic responses to noxious stimuli and providing effective analgesia [22, 23]. Surgical stimulation affects the sympathetic nerves, causing changes in plethysmographic pulse waves and $H R$, which lead to changes in SPI. Because dexmedetomidine decreases the stress response, it also decreases HR, and lower HRs increase HBI values according to the following formula: $\mathrm{SPI}=100-(0.33 \times$ HBInorm $+0.67 \times$ PPGAnorm) [4]. Dexmedetomidine decreased HR at intubation, in this study, resulting in significantly lower SPI at the same time point. Dexmedetomidine inhibits the stress of tracheal intubation, and stabilizes circulation; however, even though HR was notably lower at the beginning of surgery with dexmedetomidine, SPI values did not differ between the two groups. This finding might indicate that stress stimulus intensity was stronger than HR reduction at skin incision. Ahonen et al. [27] reported that beta blockers decrease HR, only, and do not blunt the nociceptive response. If nociceptive stimuli exceed the effect of lower HR on SPI, then SPI does not necessarily decrease, which explains why the SPI value was not affected at the beginning of surgery, in our study. The pharmacological properties of dexmedetomidine include an auxiliary analgesic effect and stress response 


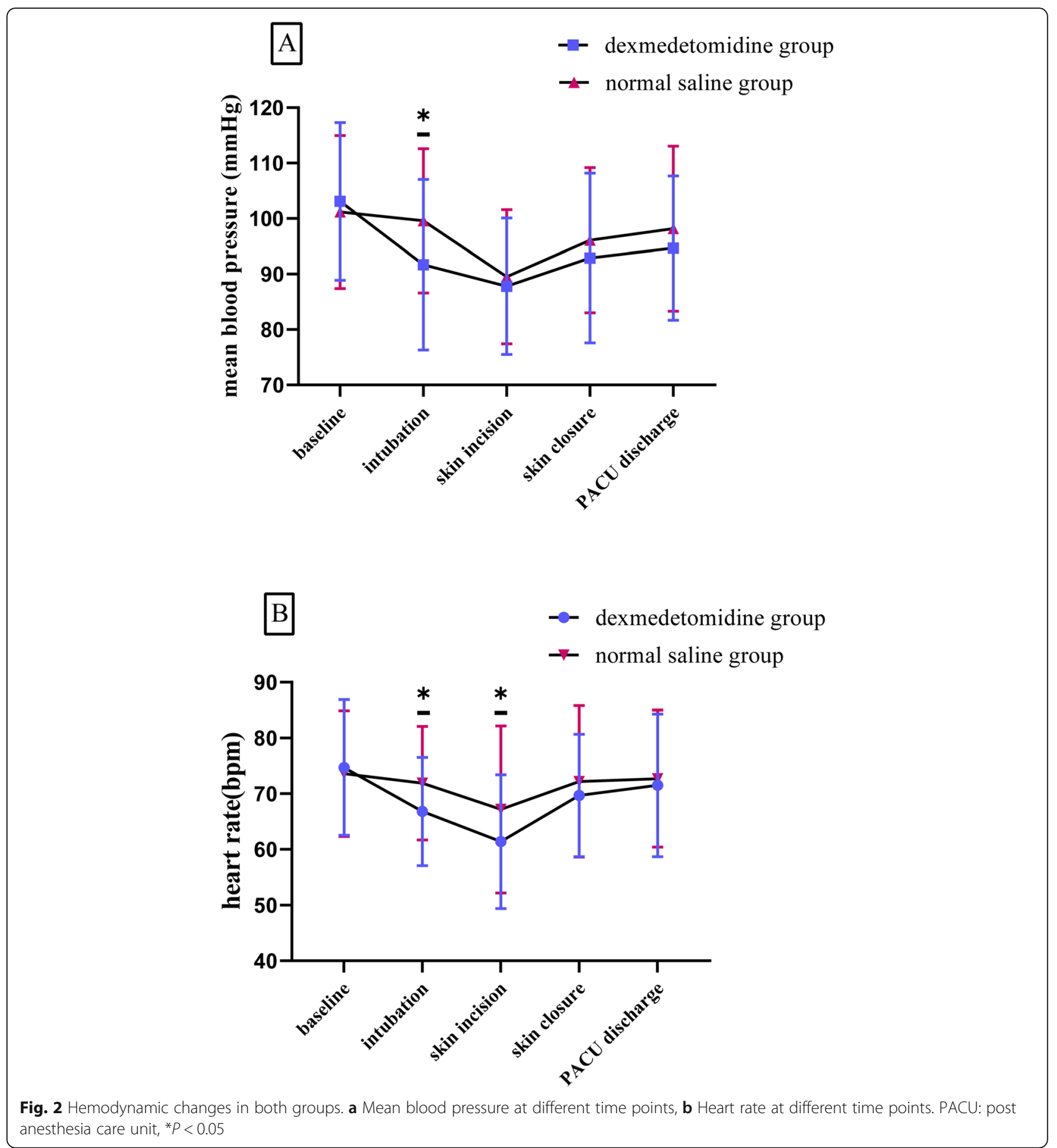

suppression, and dexmedetomidine significantly decreased the SPI value in the PACU, in our study. Therefore, postoperative adverse stimuli were well suppressed.

Previous studies indicated that SPI is correlated with NRS $[3,26,28]$. In the study, dexmedetomidine decreased SPI values. Dexmedetomidine decreased the surgical stress response and also relieved postoperative pain secondary to its analgesic effect. Therefore, SPI and NRS decreased simultaneously in the PACU. The reduction in patients' pain indicated that the surgical stress response was well suppressed, and SPI values were lower, indicating a correlation between SPI and NRS.

There are two main limitations in this study. First, dexmedetomidine was used only with a loading dose before anesthesia. Results may change with continuous 


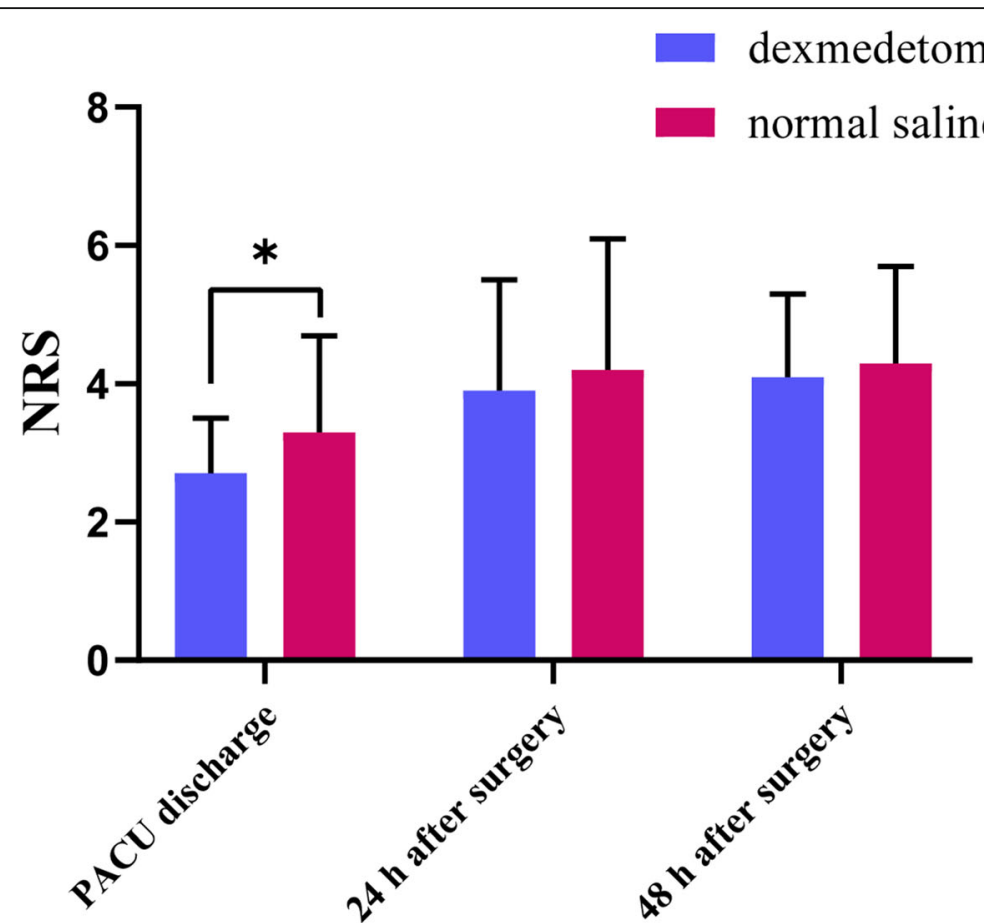

Fig. 3 Comparison of postoperative NRS pain scores between the two groups from when they left the recovery room to $48 \mathrm{~h}$ after surgery. NRS: number rating scale, PACU: post anesthesia care unit, ${ }^{*} P<0.05$

dexmedetomidine infusion during surgery following the loading dose. Second, we did not measure stress indicators such as catecholamines during surgery. Our future research plans involve addressing these limitations.

\section{Conclusion}

Dexmedetomidine decreased surgical stress and postoperative pain during moderate-intensity surgery in VATS lung lobectomy. Our results demonstrated that dexmedetomidine during general anesthesia attenuated noxious stimulation.

\section{Abbreviations}

SPI: Surgical pleth index; NRS: Number rating scale; VATS: Video-assisted thoracoscopic surgery; PPGA: Photoplethysmographic amplitude; HR: Heart rate; BMI: Body mass index; ASA: American Society of Anesthesiologists physical status grade; BP: Blood pressure; PACU: Post anesthesia care unit; OAA/S: Observer's Assessment of Alertness/Sedation; HBI: Heart beat intervals

\section{Acknowledgements}

The authors would like to thank Jun Zhao and Haitao Ma for assisting in the study.

\section{Authors' contributions}

FJ conceived and designed the study. YW, XK, FJ analyzed, interpreted the data, and carried out statistical analysis. YL wrote the manuscript. All authors participated in the study and agreed to the final version of this manuscript.

\section{Funding}

This study was supported by the Jiangsu Provincial Medical Innovation Team (CXTDA2017043 to FJ).

\section{Availability of data and materials}

The datasets used and analysed during the current study are available from the corresponding author on reasonable request.
Ethics approval and consent to participate

This study was approved by the ethics committee of our hospital, written informed consent was obtained from all patients prior to study participation.

\section{Consent for publication}

Not applicable.

\section{Competing interests}

The authors declare that they have no competing interests.

Received: 5 July 2020 Accepted: 28 September 2020

Published online: 02 October 2020

\section{References}

1. Kaplowitz J, Papadakos PJ. Acute pain management for video-assisted thoracoscopic surgery: an update. J Cardiothorac Vasc Anesth. 2012;26: $312-21$.

2. Bendixen M, Jørgensen OD, Kronborg C, Andersen C, Licht PB. Postoperative pain and quality of life after lobectomy via video-assisted thoracoscopic surgery or anterolateral thoracotomy for early stage lung cancer: a randomized controlled trial. Lancet Oncol. 2016;17:836-44.

3. Ledowski T, Burke J, Hruby J. Surgical pleth index: prediction of postoperative pain and influence of arousal. Br J Anaesth. 2016;117:371-4.

4. Huiku M, Uutela K, van Gils M, Korhonen I, Kymäläinen M, et al. Assessment of surgical stress during general anaesthesia. Br J Anaesth. 2007:98:447-55.

5. Hamunen $\mathrm{K}$, Kontinen V, Hakala E, Talke P, Paloheimo M, et al. Effect of pain on autonomic nervous system indices derived from photoplethysmography in healthy volunteers. Br J Anaesth. 2012;108:838-44.

6. Wennervirta J, Hynynen M, Koivusalo AM, Uutela K, Huiku M, et al. Surgical stress index as a measure of nociception/antinociception balance during general anesthesia. Acta Anaesthesiol Scand. 2008;52:1038-45.

7. Ledowski T, Sommerfield D, Slevin L, Conrad J, von Ungern-Sternberg BS. Surgical pleth index: prediction of postoperative pain in children? Br J Anaesth. 2017;119:979-83.

8. Carollo DS, Nossaman BD, Ramadhyani U. Dexmedetomidine: a review of clinical applications. Curr Opin Anaesthesiol. 2008;21:457-61. 
9. Venn RM, Bradshaw CJ, Spencer R, Brealey D, Caudwell E, et al. Preliminary UK experience of dexmedetomidine, a novel agent for postoperative sedation in the intensive care unit. Anaesthesia. 1999;54:1136-42.

10. Kim MH, Lee KY, Bae SJ, Jo M, Cho JS. Intraoperative dexmedetomidine attenuates stress responses in patients undergoing major spine surgery. Minerva Anestesiol. 2019;85:468-77.

11. Shamin R, Srivastava S, Rastogi A, Kishore K, Srivastava A. Effect of two different doses of Dexmedetomidine on stress response in laparoscopic Pyeloplasty: a randomized prospective controlled study. Anesth Essays Res. 2017;11:1030-4.

12. Steinthorsdottir KJ, Wildgaard L, Hansen $\mathrm{HJ}$, et al. Regional analgesia for video-assisted thoracic surgery: a systematic review. Eur J Cardiothorac Surg. 2014:45:959-66.

13. Falcoz PE, Puyraveau M, Thomas PA, et al. Video-assisted thoracoscopic surgery versus open lobectomy for primary non-small-cell lung cancer: a propensity-matched analysis of outcome from the European Society of Thoracic Surgeon database. Eur J Cardiothorac Surg. 2016;49:602-9.

14. Clarke H, Soneji N, Ko DT, et al. Rates and risk factors for prolonged opioid use after major surgery: population based cohort study. BMJ. 2014;348: g1251.

15. Fletcher $D$, Martinez $V$. Opioid-induced hyperalgesia in patients after surgery: a systematic review and a meta-analysis. Br J Anaesth. 2014;112: 991-1004.

16. Grape S, Kirkham KR, Frauenknecht J, Albrecht E. Intra-operative analgesia with remifentanil vs. dexmedetomidine: a systematic review and metaanalysis with trial sequential analysis. Anaesthesia. 2019;74:793-800.

17. Ranganathan P, Ritchie MK, Ellison MB, Petrone A, Heiraty P, Tabone LE. A randomized control trial using intraoperative dexmedetomidine during roux-en-Y gastric bypass surgery to reduce postoperative pain and narcotic use. Surg Obes Relat Dis. 2019;15:588-94.

18. Beder El, Baz MM, Farahat TEM. Intraperitoneal Levobupivacaine alone or with Dexmedetomidine for postoperative analgesia after laparoscopic cholecystectomy. Anesth Essays Res. 2018;12:355-8.

19. Kim HC, Lee YH, Jeon YT, Hwang JW, Lim YJ, et al. The effect of intraoperative dexmedetomidine on postoperative catheter-related bladder discomfort in patients undergoing transurethral bladder tumour resection: a double-blind randomised study. Eur J Anaesthesiol. 2015;32:596-601.

20. Shorrock P, Heaton T, Cochrane N, Jackson M, Lund K, et al. The effects of dexmedetomidine on postoperative pain. Anaesthesia. 2015;70:372.

21. Peng K, Liu HY, Wu SR, Cheng H, Ji FH. Effects of combining Dexmedetomidine and opioids postoperative intravenous patient-controlled analgesia: a systematic review and meta-analysis. Clin J Pain. 2015;31:1087-104.

22. Bergmann I, Göhner A, Crozier TA, Hesjedal B, Wiese CH. Surgical pleth index-guided remifentanil administration reduces remifentanil and propofol consumption and shortens recovery times in outpatient anaesthesia. Br J Anaesth. 2013;110:622-8.

23. Won YJ, Lim BG, Lee SH, Park S, Kim H, et al. Comparison of relative oxycodone consumption in surgical pleth index-guided analgesia versus conventional analgesia during sevoflurane anesthesia: a randomized controlled trial. Medicine (Baltimore). 2016:95:e4743.

24. Gruenewald M, Herz J, Schoenherr T, Thee C, Steinfath M, et al. Measurement of the nociceptive balance by analgesia nociception index and surgical Pleth index during sevoflurane-remifentanil anesthesia. Minerva Anestesiol. 2015;81:480-9.

25. Colombo R, Raimondi F, Corona A, Rivetti I, Pagani F, et al. Comparison of the surgical Pleth index with autonomic nervous system modulation on cardiac activity during general anaesthesia: a randomised cross-over study. Eur J Anaesthesiol. 2014;31:76-84

26. Thee C, llies C, Gruenewald M, Kleinschmidt A, Steinfath M, et al. Reliability of the surgical Pleth index for assessment of postoperative pain: a pilot study. Eur J Anaesthesiol. 2015:32:44-8.

27. Ahonen J, Jokela R, Uutela K, Huiku M. Surgical stress index reflects surgical stress in gynaecological laparoscopic day-case surgery. Br J Anaesth. 2007; 98:456-61

28. Ledowski T, Ang B, Schmarbeck T, Rhodes J. Monitoring of sympathetic tone to assess postoperative pain: skin conductance vs surgical stress index. Anaesthesia. 2009;64:727-31.

\section{Publisher's Note}

Springer Nature remains neutral with regard to jurisdictional claims in published maps and institutional affiliations.

\section{Ready to submit your research? Choose BMC and benefit from:}

- fast, convenient online submission

- thorough peer review by experienced researchers in your field

- rapid publication on acceptance

- support for research data, including large and complex data types

- gold Open Access which fosters wider collaboration and increased citations

- maximum visibility for your research: over $100 \mathrm{M}$ website views per year

At $\mathrm{BMC}$, research is always in progress.

Learn more biomedcentral.com/submissions 